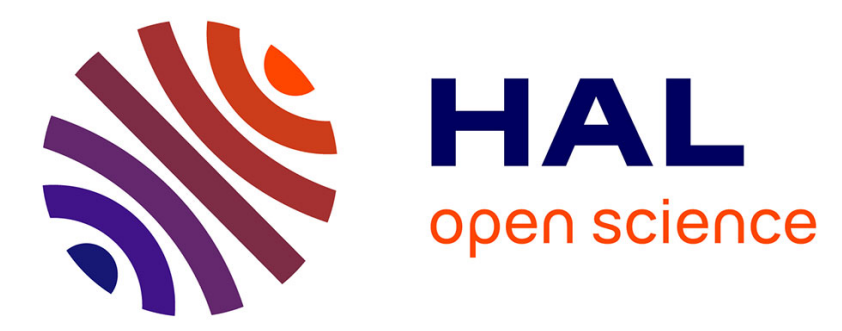

\title{
Stern Layer Structure and Energetics at Mica-Water Interfaces
}

Ian C. Bourg, Sang Soo Lee, Paul Fenter, Christophe Tournassat

\section{To cite this version:}

Ian C. Bourg, Sang Soo Lee, Paul Fenter, Christophe Tournassat. Stern Layer Structure and Energetics at Mica-Water Interfaces. Journal of Physical Chemistry C, 2017, 121 (17), pp.9402 - 9412. 10.1021/acs.jpcc.7b01828 . insu-01580064

\section{HAL Id: insu-01580064 \\ https://hal-insu.archives-ouvertes.fr/insu-01580064}

Submitted on 30 Sep 2020

HAL is a multi-disciplinary open access archive for the deposit and dissemination of scientific research documents, whether they are published or not. The documents may come from teaching and research institutions in France or abroad, or from public or private research centers.
L'archive ouverte pluridisciplinaire HAL, est destinée au dépôt et à la diffusion de documents scientifiques de niveau recherche, publiés ou non, émanant des établissements d'enseignement et de recherche français ou étrangers, des laboratoires publics ou privés. 


\title{
Stern Layer Structure and Energetics at Mica-Water Interfaces
}

\author{
Ian C. Bourg*, ${ }^{*}$, Sang Soo Lee ${ }^{\S}$, Paul Fenter ${ }^{\S}$, Christophe Tournassat ${ }^{\ddagger}$ \\ ${ }^{\dagger}$ Princeton University, Department of Civil and Environmental Engineering and Princeton Environmental Institute, Prince- \\ ton, NJ 08544, USA \\ ${ }^{\S}$ Argonne National Laboratory, Chemical Sciences and Engineering Division, Argonne, IL 60439, USA

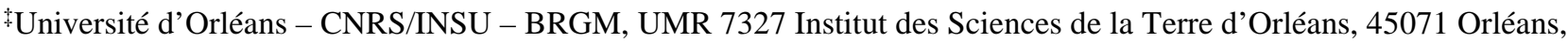 \\ France
}

\begin{abstract}
The screening of surface charge by dissolved ions at solid-liquid interfaces-in the region of interfacial fluid known as the electrical double layer (EDL) — plays a recurrent role in surface science, from ion adsorption to colloidal mechanics to the transport properties of nanoporous media. A persistent unknown in theories of EDL-related phenomena is the structure of the Stern layer, the near-surface portion of the EDL where water molecules and adsorbed ions form specific, short-range interactions with surface atoms. Here, we describe a set of synchrotron X-ray reflectivity (XRR) experiments and molecular dynamics (MD) simulations carried out in identical conditions, for a range of $0.1 \mathrm{M}$ alkali chloride (Li-, Na-, K-, Rb-, or CsCl) solutions on the basal surface of muscovite mica, a mineral isostructural to phyllosilicate clay minerals and one of the most widely-studied reference surfaces in interfacial science. Our XRR and MD simulation results provide a remarkably consistent view of the structure and energetics of the Stern layer, with some discrepancy on the fraction of the minor outer-sphere component of Rb and on the adsorption energetics of $\mathrm{Li}$. The results of both techniques, along with surface complexation model (SCM) calculations, provide insight into the sensitivity of water structure and ion adsorption to surface topography and the type of adsorbed counter-ion.
\end{abstract}

\section{INTRODUCTION}

The electrical double layer (EDL) at solid-water interfaces - the layer of interfacial water and electrolyte ions that screen surface charge - is a ubiquitous feature of natural and engineered systems containing water and colloids, nanoparticles, or nanopores. It plays important roles in nanofluidics, ${ }^{1,2}$ nanofiltration, ${ }^{3}$ molecular biology, ${ }^{4,5}$ colloidal mechanics, ${ }^{6,7}$ catalysis, ${ }^{8}$ cement degradation, ${ }^{9}$ aquatic geochemistry, ${ }^{10,11}$ the phase transitions of water near solid surfaces, ${ }^{12}$ and the poro-mechanics and transport properties of soils and sedimentary rocks. ${ }^{13,14}$

The EDL is often conceptually subdivided into two regions: a Stern layer located within two water monolayers ( $\sim 6$ $\AA$ ) of the interface in which ions adsorb as inner- and outersphere surface complexes (ISSC, OSSC) and a diffuse layer located beyond the first two water monolayers in which a diffuse cloud of ions screens the remaining uncompensated surface charge. ${ }^{15,16}$ The diffuse layer has been extensively studied and is relatively well understood: there, water has bulk-liquid-like properties ${ }^{17-20}$ and the distribution of ions is consistent with the Poisson-Boltzmann equation with corrections for specific ion-ion interactions. ${ }^{16,21,22}$ Detailed understanding of the Stern layer remains more elusive, ${ }^{6,23-26}$ because the behavior of water and ions in this layer can be exquisitely sensitive to details of the surface topography, surface charge distribution, ion-ion correlations, and interfacial hydrogen bonding arrangement. ${ }^{26-29}$

The major challenge in developing a predictive understanding of the Stern layer is the difficulty of characterizing with $\AA$-scale resolution the inter-related distributions of water molecules and electrolyte ions within $1 \mathrm{~nm}$ from a solid surface. Experimental studies of the EDL structure have relied extensively on indirect or aggregate measures such as co-ion exclusion, ${ }^{15}$ electrokinetic, ${ }^{30}$ electrochemical, ${ }^{16}$ and second harmonic or sum frequency generation (SHG/SFG) measurements, ${ }^{31}$ the interpretation of which is sensitive to the choice of EDL model. The EDL structure also has been examined using high-resolution mechanical measurements including surface force apparatus (SFA), ${ }^{23,32}$ three-dimensional scanning force microscopy, ${ }^{33}$ atomic force microscopy (AFM), ${ }^{26,29}$ and frequencymodulated atomic force microscopy (FM-AFM) measurements. ${ }^{34-36}$ Unfortunately, the EDL features revealed by these techniques are inherently disturbed by the measurement, particularly at very short $(<1 \mathrm{~nm})$ distances from the surface. ${ }^{24,37}$

Direct, non-invasive measurements of the EDL structure have been achieved using synchrotron X-ray techniques including the combination of X-ray reflectivity (XRR) and resonant anomalous XRR (RAXR) $)^{38-41}$ and X-ray standing waves (XSW). ${ }^{21,42-44}$ Resonant anomalous XRR, in particular, has played a key role over the last decade in revealing sub- $\AA$-scale resolution views of the vertical density distributions of certain electrolyte ions (e.g., $\mathrm{Rb}^{+}, \mathrm{Sr}^{2+}$ ) adsorbed at the negatively charged surfaces of mica, ${ }^{25,38,45,46}$ quartz, ${ }^{47}$ and rutile. $^{48}$

Concurrently with the experimental studies highlighted above, molecular dynamics (MD) simulations have emerged as a useful tool for predicting the distribution and dynamics 
of ions and water molecules on charged surfaces. ${ }^{19,49-52}$ Molecular dynamics simulations are well suited for examining EDL properties, because they probe the range of length and time scales (up to tens of nanometers and hundreds of nanoseconds) on which the behavior of individual molecules gives rise to collective structure and dynamics near charged surfaces. Molecular dynamics and ab initio MD simulations powerfully complement synchrotron X-ray techniques by providing an atom-by-atom view of the time- and spaceaveraged coordination structures revealed by X-rays. ${ }^{50,53,54}$ Comparisons of XRR and MD simulation results have the potential to help quantify the accuracy of both techniques: in the case of MD simulations, the main source of uncertainty is the choice of inter-atomic potential parameters, ${ }^{55,56}$ in the case of XRR analyses, challenges are associated with the finite resolution of the experimental measurement, the difficulty of creating atomically smooth surfaces, and the challenge of interpreting XRR data in the context of atomic-scale density profiles due to the phase problem of crystallography. ${ }^{57}$ To date, few direct comparisons of XRR and MD simulation results have been carried out, so that the absolute accuracy associated with each technique has not been quantitatively assessed through stringent cross-validation of the two methodologies. ${ }^{49,56,58-61}$

Here, we present new MD simulation and XRR results on the structure of the EDL formed by alkali chloride solutions on the basal surface of muscovite mica, an atomicallysmooth surface isostructural to many clay minerals ${ }^{62}$ and widely used as a reference system in interfacial science. ${ }^{26,32,34,50,63-65}$ Our MD simulations were carried out using inter-atomic potential parameters known to accurately describe the structure and dynamics of water and ions in clay and silica nanopores. ${ }^{55,56,66-69}$ Synchrotron XRR measurements were carried out at the Advanced Photon Source (APS) using well-established methodologies. ${ }^{25,46}$ Our experimental and simulation results were obtained at identical conditions, namely for $0.1 \mathrm{M} \mathrm{MCl}$ aqueous solutions $(\mathrm{M}=$ $\mathrm{Li}, \mathrm{Na}, \mathrm{K}, \mathrm{Rb}$, or $\mathrm{Cs}$ ) on the basal surface of muscovite mica at ambient conditions. The present study, to our knowledge, is the first to show that MD simulations can accurately predict XRR data for ion adsorption at charged mineral-water interfaces. Our results provide a detailed view of the structure of the Stern layer at mica-water interfaces and its dependence on the type of adsorbed cation.

\section{METHODOLOGY}

Molecular dynamics (MD) simulations were carried out on the supercomputers at the National Energy Research Scientific Computing Center (NERSC) using the code LAMMPS ${ }^{70}$ Briefly, we simulated a 60 - $\AA$ thick slab of mica in contact with a 120 - $\AA$ thick slab of liquid water in a $52.1 \times$ $45.2 \times 180.0 \AA^{3}$ simulation cell with periodic boundary conditions (Fig. 1). A muscovite mica crystal of the $2 \mathrm{M}_{1}$ polytype with unit cell formula $\mathrm{KAl}_{2}\left(\mathrm{Si}_{3} \mathrm{Al}\right) \mathrm{O}_{10}(\mathrm{OH})_{2}$ was constructed based on neutron diffraction data. ${ }^{71}$ Isomorphic substitutions of $\mathrm{Si}$ by $\mathrm{Al}$ were randomly distributed in the mica structure with the constraint that substitutions did not occur in neighboring tetrahedra. Interatomic interactions were described using the SPC/E water model, ${ }^{72}$ the CLAYFF model for mica, ${ }^{73}$ and the Dang model of chloride and alkali metal ions. ${ }^{74,75}$ Interatomic interactions were resolved in real space up to a distance of $12.0 \AA \AA$. Long-range Coulomb interactions beyond $12.0 \AA$ were resolved in reciprocal space using the particle-particle/particle-mesh (PPPM) technique with an accuracy of $99.99 \%$. The mica slab was modeled as a rigid entity with the exception of structural $\mathrm{H}$ atoms and interlayer $\mathrm{K}$ ions. The number of water molecules in the simulation cell was such that pressure equaled zero in the bulk-liquid-like water region in the simulation with adsorbed $\mathrm{Na}$. Each system was equilibrated for $2 \mathrm{~ns}$, and then simulated for 10 ns with a 1 fs time step in the NVT ensemble at $T=$ $298 \mathrm{~K}$.

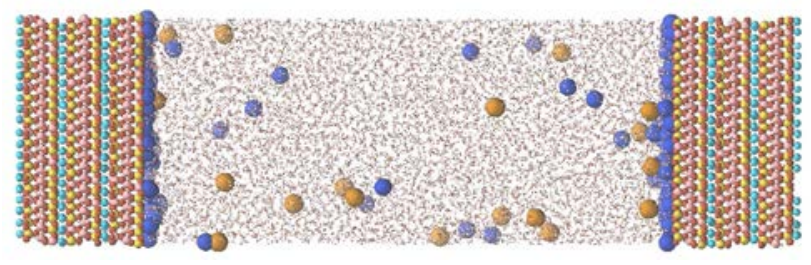

Figure 1. Snapshot of our MD simulation of a $0.1 \mathrm{M} \mathrm{NaCl}$ solution in contact with mica. Atoms in the mica structure are shown as yellow $(\mathrm{Si})$, pink $(\mathrm{Al})$, red $(\mathrm{O})$, white $(\mathrm{H})$, and light blue spheres (K). Water molecules are shown as transparent red and white sticks. Ions are shown as dark blue ( $\mathrm{Na})$ and orange spheres (Cl).

In addition to our standard MD simulations, we used the thermodynamic integration (TI) technique to examine the energetics of cation exchange at the mica-water interface. ${ }^{76,77}$ Briefly, our TI calculations consisted in modeling a Csbearing mica at zero ionic strength (no chloride co-ions). Then, we slowly morphed the adsorbed Cs ions into Rb, K, $\mathrm{Na}$, and eventually Li by linearly adjusting their Van der Waals interatomic potential parameters in a series of 75 small transformations. Each small transformation step was followed by 0.2 ns of equilibration and 0.8 ns of simulation in the $\mathrm{NP}_{z} \mathrm{~T}$ ensemble at $T=298 \mathrm{~K}$ and $P_{\mathrm{z}}=0$ bar. The free energy change associated with each small transformation was calculated using established methodologies as described in the Supporting Information (SI). The resulting free energies $(\Delta F)$ are not strictly equivalent to measured Gibbs free energies $(\Delta G)$, because our TI simulations were carried out in the $N P_{z} T$ ensemble (constant pressure in the $z$ direction, but fixed simulation cell size in the $x$ and $y$ directions). Nevertheless, our predicted values of $\Delta F_{\mathrm{aq}}^{\mathrm{Cs} / \mathrm{Rb}}=-26.6 \pm 0.2 \mathrm{~kJ}$ $\mathrm{mol}^{-1}, \Delta F_{\mathrm{aq}}^{\mathrm{Cs} / \mathrm{K}}=-42.5 \pm 0.3 \mathrm{~kJ} \mathrm{~mol}^{-1}, \Delta F_{\mathrm{aq}}^{\mathrm{Cs} / \mathrm{Na}}=-113.4 \pm 0.9$ $\mathrm{kJ} \mathrm{mol}^{-1}$ and $\Delta F_{\mathrm{aq}}^{\mathrm{Cs} / \mathrm{Li}}=-242.8 \pm 1.4 \mathrm{~kJ} \mathrm{~mol}^{-1}$ are close to the experimental values of $\Delta G_{\mathrm{aq}}^{\mathrm{Cs} / \mathrm{i}}(-25,-45,-115$, and $-225 \mathrm{~kJ}$ $\mathrm{mol}^{-1}$, respectively) ${ }^{78}$ except in the case of Li.

$\mathrm{X}$-ray reflectivity measurements were carried out at beamline 6-ID-B, Advanced Photon Source (APS), Argonne National Laboratory. Gem-quality muscovite crystals (Asheville-Schoonmaker Mica Company) in a dimension of $25 \times$ $25 \times 0.2 \mathrm{~mm}^{3}$ were cleaved using tape to expose fresh basal planes. The cleaved crystals were rinsed with deionized water and then mounted in an X-ray thin-film cell. ${ }^{39,46}$ Aqueous solutions ( $0.1 \mathrm{M} \mathrm{MCl}$, where $\mathrm{M}=\mathrm{Li}, \mathrm{Na}, \mathrm{K}, \mathrm{Rb}$, or $\mathrm{Cs}$ ) were prepared by dissolving $\geq 99 \%$ alkali-metal chloride salts in deionized water. One of these experimental solutions was injected into the thin-film cell containing a mica crystal, which was allowed to react with the solution for about 30 minutes. After the reaction, the extra solution was drained by gravity, and the cell maintained a several- $\mu$ m-thick solution film on top of the mica surface. ${ }^{39,46}$ The sample cell was mounted in a 6-circle Huber diffractometer for X-ray reflec- 
tivity experiments. A monochromatic X-ray beam [at a photon energy of either $16 \mathrm{keV}$ (for $\mathrm{Li}, \mathrm{Na}, \mathrm{K}$, and $\mathrm{CsCl}$ experiments) or $17 \mathrm{keV}$ (for the $\mathrm{RbCl}$ experiment)] reflected from the mica surface was collected using an X-ray CCD detector $^{79}$ as a function of momentum transfer $q$, defined as $q$ $=4 \pi \sin (2 \theta / 2) / \lambda$ where $2 \theta$ is the angle between the incident and reflected $\mathrm{X}$-ray beams and $\lambda$ is the wavelength of X-rays $(\lambda=0.775$ and $0.729 \AA$ at 16 and $17 \mathrm{keV}$, respectively). Resonant anomalous X-ray reflectivity measurements are reported for a $3 \mathrm{mM} \mathrm{RbCl}$ solution. Briefly, the elastic reflectivity signal measured as a function of photon energy near the Rb K-absorption edge energy $\left(E_{o}=\sim 15.21 \mathrm{keV}\right)$ at selected $q$ provides additional sensitivity to the elementspecific distribution of the adsorbed Rb ions. ${ }^{46}$ The XRR and RAXR data were analyzed following methodologies described in the Supporting Information (SI).

\section{RESULTS AND DISCUSSION}

Vertical density profiles of the electrical double layer. A key output of both XRR experiments and MD simulations is the electron density profile in the direction normal to the interface. ${ }^{61}$ In Fig. 2, we compare our predicted (MD) and measured (XRR) electron density profiles for $0.1 \mathrm{M}$ alkali chloride solutions on the mica basal surface. Distances are normalized such that $z=0$ corresponds to the average height of basal surface $\mathrm{O}$ atoms. ${ }^{39,50}$ The expected location of the first, second, and third water monolayers $\left(Z_{\mathrm{W} 1} \approx 3.0 \pm 1.5 \AA\right.$, $z_{\mathrm{W} 2} \approx 6.0 \pm 1.5 \AA, z_{\mathrm{W} 3} \approx 9.0 \pm 1.5 \AA$ ) are indicated on the figure based on the known thickness of a water monolayer in the interlayer nanopores of swelling clay minerals $(\approx 3.0$ $\AA){ }^{69,80,81}$ The curves shown in Fig. 2 reflect a weighted sum of the atomic density distribution of all atoms, with a weighting factor of the atomic number to reflect the profile that is probed by XRR. The curves primarily reflect the density profile of water $\mathrm{O}$ atoms and of the heaviest adsorbed ions (Cs, Rb, K).
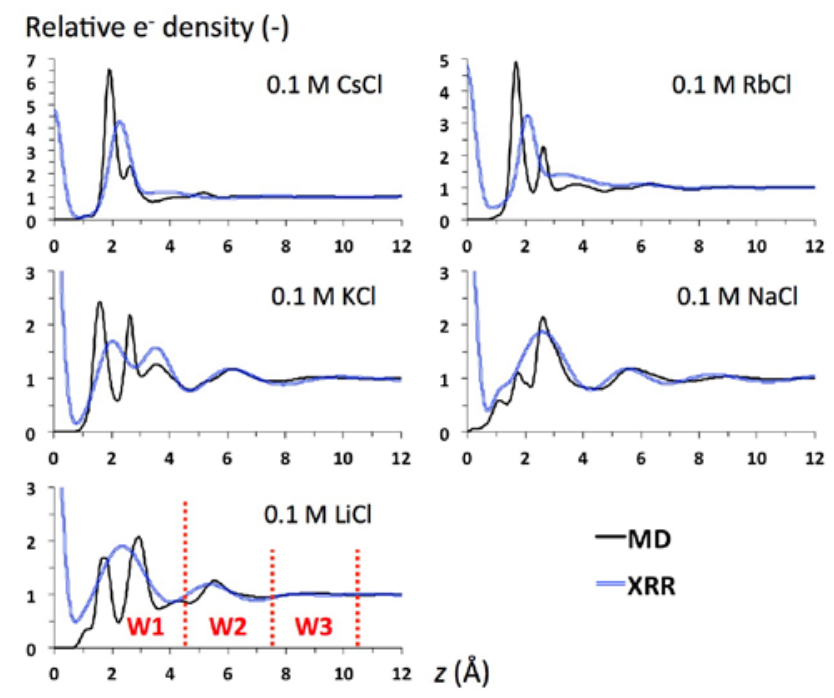

Figure 2. Electron density profile (normalized to the value in bulk liquid water) as a function of distance from the mica surface as determined by a conventional model fit to our XRR data (blue lines) or predicted by MD simulation (black lines).

The XRR and MD simulation results shown in Fig. 2 agree on several features. Both techniques indicate that water density layering extends roughly three water layers from the mica surface, in agreement with previous studies of micawater ${ }^{58,82}$ and other solid-water interfaces. ${ }^{17,52,83}$ In the second water layer $(z=4.5$ to $7.5 \AA$ ), both techniques predict similar density profiles in the case of $\mathrm{Li}, \mathrm{Na}$, and $\mathrm{K}$ counterions. In the first water layer $(z<4.5 \AA$ ), both techniques roughly agree on the regions of greater electron density, but the MD simulations systematically predict a more structured electron density profile, partly because the experimental curves are inherently broadened by the finite resolution $(\sim 0.6$ $\AA$ ) of the XRR measurements. ${ }^{46,59}$

To compare more directly our XRR and MD simulation results, we used our MD simulation results on the structure of interfacial water (black lines in Fig. 2) to calculate the associated XRR data. ${ }^{61}$ The relaxation of the mica structure near the interface was modeled using standard XRR data analysis methodologies (SI). The resulting comparison provides a stringent test of the ability of the inter-atomic potential models used in our MD simulations to accurately predict the structure of interfacial water. The comparison between measured and MD-predicted XRR data is shown in Fig. 3. The results are consistent across the full range of momentum transfer for all five counter-ions with quality of fits that are commensurate with that obtained with the fitting routine used in our previous XRR studies ${ }^{46}$ as described in the Supporting Information. The good agreement between our XRR and MD simulation results in Fig. 3 provides a strong crossvalidation of the consistency of our experimental and simulation methodologies.

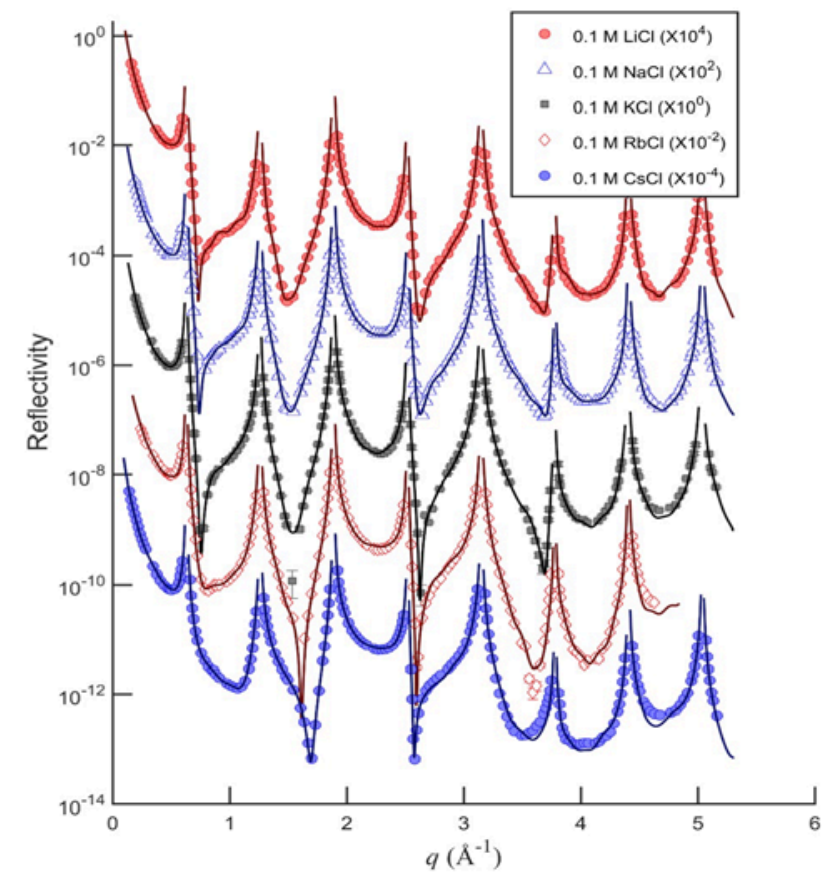

Figure 3. In-situ XRR data at the muscovite (001) - $0.1 \mathrm{M}$ alkali chloride solution interfaces. The solid lines are calculated using the MD-derived water profiles, ${ }^{84}$ as described in the Supporting Information. Each dataset is scaled vertically for clarity.

Structure of the Stern layer. Our MD simulation results, validated by our XRR data, provide a detailed view of cation adsorption in the Stern layer. All alkali metals adsorb predominantly (90 to $99 \%$ ) as two types of inner-sphere surface complexes (ISSC1, ISSC2). The height of each ISSC species above the mica-water interface increases with ionic radius, 
as expected if this height is controlled by short-range repulsion between the adsorbed ion and surface $\mathrm{O}$ atoms. ${ }^{45}$ The only exception is in the case of the ISSC1 species of lithium (Fig. 4). The first type of complex (ISSC1) is strongly favored by large cations (Cs, Rb, K), but not by small cations (Na, Li). To determine the identity of the two types of ISSC, we calculated two-dimensional maps of the distribution of ISSC1 and ISSC2 species on the mica surface. The results (illustrated in Fig. 5 in the case of Cs) indicate that the first type of surface complex, ISSC1, corresponds to cations located at the center of the ditrigonal cavities of the siloxane surface, particularly those cavities that are bordered by two or more isomorphic substitutions of Si by Al. The second type of surface complex, ISSC2, corresponds to cations that sit directly above a structural charge site, on a so-called "triad" of surface $\mathrm{O}$ atoms. ${ }^{65,85}$ The two types of complexes have previously been noted in studies of $\mathrm{K}$ and Cs in smectite interlayers ${ }^{85}$ and of $\mathrm{K}$ on mica surfaces. ${ }^{58}$ Our finding that $\mathrm{Li}$ and $\mathrm{Na}$ prefer the triad site (ISSC2) whereas larger alkali metals prefer the cavity site (ISSC1) is consistent with AFM maps of the distribution of adsorbed alkali metals at the mica-water interface. ${ }^{26,65}$ The preference of $\mathrm{Li}$ and $\mathrm{Na}$ for the triad site likely reflects the preference of the small alkali metals for an oxygen coordination number $N_{\mathrm{O}}$ smaller than six. ${ }^{86}$ Density maps of Li ISSC1 (Fig. SI2) confirm that lithium does not fit snugly in the center of the cavity: instead, it adopts an off-center position near an edge of the cavity.

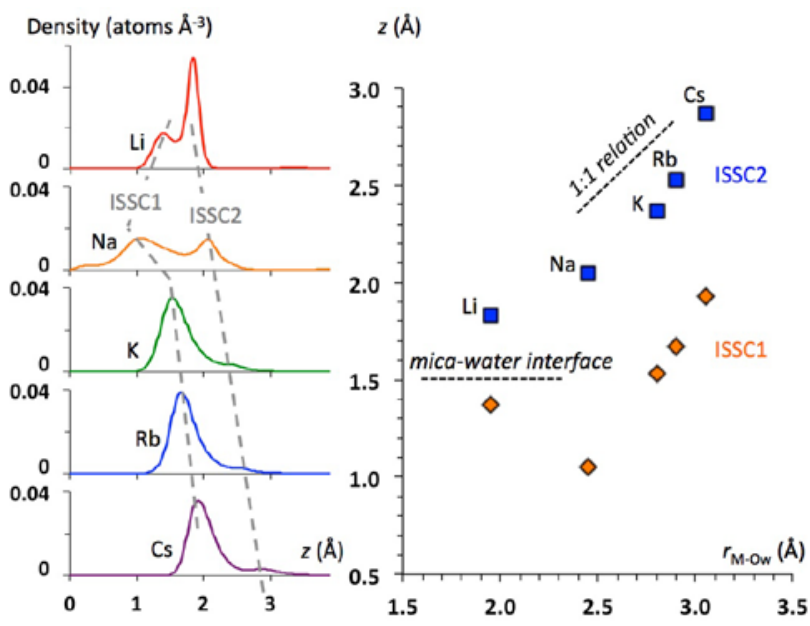

Figure 4. Left: MD simulation prediction of the density profile of the five alkali metals at the mica-water interface. Right: $z$ coordinate of ISSC density peaks, plotted as a function of the first-shell metal-oxygen distance in liquid water $r_{\mathrm{M}-\mathrm{Ow}}$.

Our MD simulation results also provide insight into the structure of water in the Stern layer. In Fig. 6, we show the density profiles of water $\mathrm{O}$ atoms as a function of distance from the surface for mica in contact with Na-, K-, Rb-, and Cs-containing solutions. With all five counter-ions, water exhibits a strong density layering at the mica surface with a periodicity of $3.02 \pm 0.03 \AA$. This periodicity is identical to that derived from our XRR data in conditions where the XRR signal most directly reflects the water structure (2.81 \pm $0.28 \AA$, on average, for mica with adsorbed $\mathrm{Li}$ and $\mathrm{Na}$ ). It also agrees with the values obtained from MD simulation studies of water on the surfaces of other minerals including quartz $(3.0 \pm 0.4 \AA)^{18}$ and smectite $(3.1 \pm 0.3 \AA) .{ }^{14}$ However, it is significantly larger than the values indirectly derived from the mechanical properties of water films confined between mica surfaces $\left(2.5 \pm 0.3 \AA\right.$ by SFA $^{63}$ and $2.65 \pm$ $0.25 \AA$ by shear force microscopy). ${ }^{87}$ Water density between $z=3$ and $7 \AA$ is significantly affected by the type of adsorbed cation, with no clear trend, whereas water density layering beyond the first two monolayers $(z>7 \AA$ ) becomes insensitive to the choice of cation. This observation is consistent with experimental results showing that ions have little impact on the structure and dynamics of liquid water beyond their first solvation shell ${ }^{88}$ and, also, with the suggestion that the Stern layer can be viewed, to some extent, as a distinct fluid phase. . $^{2,89,90}$

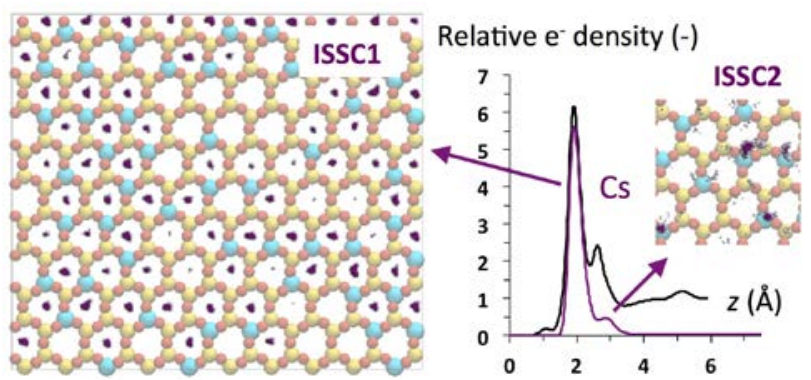

Figure 5. Graph: electron density profile as a function distance from the mica surface (black line) and contribution from the counter-ion (purple line) predicted by MD simulation in the case of Cs-bearing mica. The figure on the left and inset on the right show xy density maps of ISSC1 and ISSC2 species on one of the mica surfaces (purple), overlaid on an image of surface $\mathrm{O}$ atoms (red spheres) and underlying $\mathrm{Si}$ and $\mathrm{Al}$ atoms (yellow and blue spheres). Regions where Cs atomic density $\rho_{\text {Cs }}>0.5 \times \rho_{\text {Oow,bulk }}$ and $>3 \times$ oow,bulk ( $\rho$ ow,bulk being the density of $\mathrm{O}$ atoms in bulk liquid water) are shown in light and dark purple, respectively.

The first water monolayer contains three well-defined sublayers at different distances from the surface: $z_{\mathrm{W} 1.1}=1.73 \pm$ $0.04, z_{\mathrm{W} 1.2}=2.62 \pm 0.01$, and $z_{\mathrm{W} 1.3}=3.1$ to $3.9 \AA$. In the case of sub-layer $\mathrm{W} 1.3$, distance from the surface increases with the size of the adsorbed cation. Snapshots of the interfacial water structure show that the three sub-layers correspond to first-layer water molecules that donate two, one, or no hydrogen bonds to the siloxane surface, respectively, as previously noted for water on mica and smectite surfaces. ${ }^{19,50,58,91}$ The existence of at least two sub-layers within the first water monolayer on mica, at least one of which has an epitaxial relation with surface $\mathrm{O}$ atoms, is consistent with scanning polarization force microscopy (SPFM) studies of submonolayer water films adsorbed at mica-air interfaces. ${ }^{64}$ The peak positions ( $z$ values) and relative amplitudes of layers W1.1 and W1.2 are close to those measured by neutron diffraction with isotopic substitution (NDIS) for the interlayer nanopores of Li-vermiculite (where $z_{\mathrm{W} 1.1}=1.93$ and $z_{\mathrm{W} 1.2}$ $=2.85 \AA) .{ }^{92}$ Maps of water O density in planes parallel to the surface (Fig. 6) show that first layer water molecules are strongly templated by the $\mathrm{O}$ atoms of the siloxane surface: W1.1 molecules occupy ditrigonal cavities that are not occupied by ISSC1 cations, W1.2 molecules sit directly atop basal O atoms, and W1.3 molecules are loosely localized above rings of surface $\mathrm{O}$ atoms, in agreement with highresolution AFM and FM-AFM images ${ }^{35,64}$ and previous MD simulations. $^{37,50}$ The first two peaks of the water $\mathrm{O}$ density profile are almost identical in the case of the mica surface with adsorbed $\mathrm{Na}, \mathrm{K}, \mathrm{Rb}$, and $\mathrm{Cs}$, indicating that the struc- 
ture of W1.1 and W1.2 water is primarily dictated by the surface (more precisely, by surface $\mathrm{O}$ atoms), not by adsorbed cations. With adsorbed $\mathrm{Li}$, the first density peak is significantly taller, because Li has a much smaller tendency than other cations to occupy the hexagonal cavities. Our results confirm previous findings that hydrogen bonding with surface $\mathrm{O}$ atoms plays an important role in controlling near-surface water structure. ${ }^{50,93}$ They also indicate that this hydrogen bonding can be patchy, because of heterogeneous charge distribution in the mineral structure, and sensitive to the type of adsorbed counter-ion, because the preferred coordination structures of different ions are unequally accommodated by the surface topography.

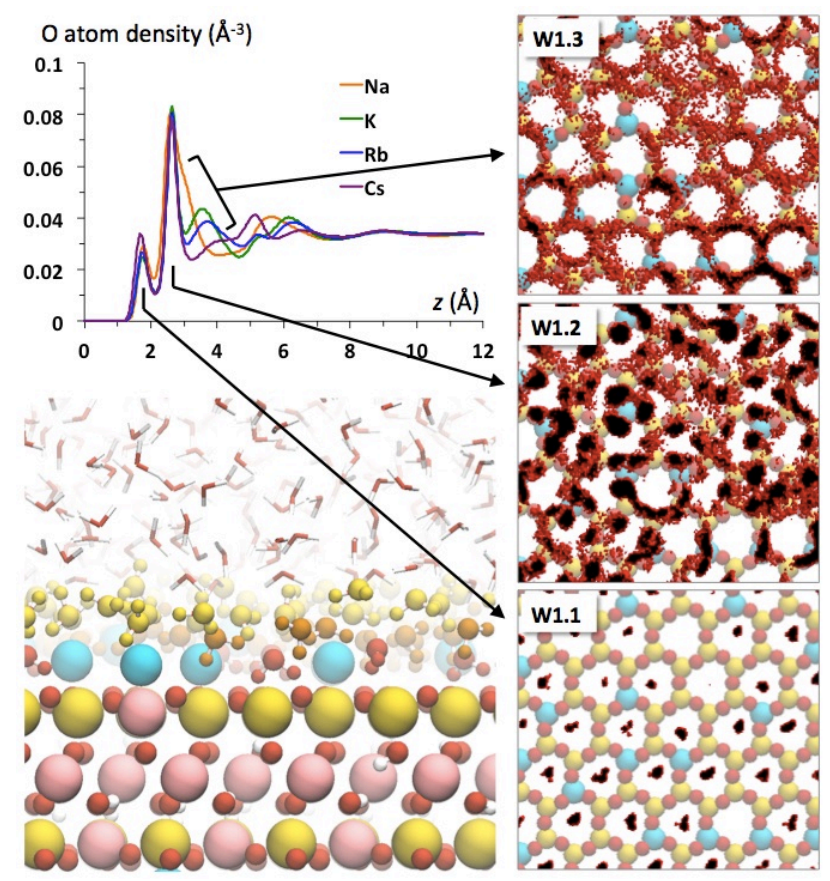

Figure 6. Top left: water $\mathrm{O}$ density profile as a function of distance from the mica surface for Na-, K-, Rb-, and Cs-bearing mica. Bottom left: MD simulation snapshot of the mica-water interface (same color scheme as in Fig. 1, except that water molecules in sub-layers W1.1, W1.2, and W1.3 are shown as red, orange, and yellow spheres). Right: $x y$ density maps of water molecules in sub-layers W1.1, W1.2, and W1.3 on a portion of one of the mica surfaces (red: $\rho$ ow $>$ pow,bulk; black:

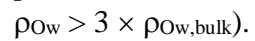

Sensitivity of interfacial structure to MD simulation parameters. Comparison of our simulation predictions with those of previous MD or Monte Carlo (MC) simulations (Table SI3) indicates that the coordination of adsorbed ions is particularly sensitive to surface topography and to the extent of delocalization of the negative charge arising from isomorphic substitutions. The first point is illustrated by the difference between our MD simulation results and those of other studies that used the CLAYFF model. ${ }^{50,94-96}$ Previous simulations with the CLAYFF model used a flexible mica structure and are known to predict an unphysical relaxation of the ditrigonal cavities. As shown in Table SI3, this relaxation causes ISSC1 ions to penetrate more deeply into the cavities, particularly in the case of the smallest ions, $\mathrm{Li}$ and $\mathrm{Na}$. The second point is illustrated by the difference between our results, those obtained with the Skipper force field (SFF), ${ }^{58,91,97-99}$ and those obtained with the Kawamura force field (KFF). ${ }^{51,59,60}$ The relative stability of ISSC1 species is greatest in the KFF model, whereas the relative stability of ISSC2 species (where the cation is located further from the bulk solid structure, but closer to the nearest isomorphic substitution) is greatest in the SFF model. These differences reflect the increase (from 0.15 to 0.525 and 1.0 on the KFF, CLAYFF, and SFF models, respectively) in the fraction of negative charge arising from isomorphic substitutions that remains localized on the metal site.

With regard to the structure of Stern layer water, all models predict the existence of three ordered water layers, with the first layer consisting of two or three sub-layers. The locations of individual water peaks are broadly consistent between these studies, the main difference being the disappearance of the W1.3 peak in SFF model predictions. The relative amplitudes of the first-layer water peaks, however, are highly sensitive to the choice of water model. In particular, surface coverage associated with the main water O density peak (sub-layer W1.2) ranges from about 0.05 to 0.13 atoms per $\AA^{3}$, depending on the choice of force field, for mica with adsorbed $\mathrm{K}$. The amplitude of this peak tends to increase with the similarity between the partial charges of $\mathrm{O}$ atoms in water and on the siloxane surface, in agreement with the expectation that the surface may have less tendency to disrupt the hydrogen-bond network of water if surface $\mathrm{O}$ atoms are more similar to water $\mathrm{O}$ atoms.

Energetics of Stern layer adsorption. To further crossvalidate our XRR and MD simulation methodologies, we compared measured and predicted energetics of ion exchange at the mica-water interface. Experimental data on the Gibbs free energies of cation exchange at the mica-water interface were reported by Lee et $\mathrm{al}^{25}$ based on resonant anomalous X-ray reflectivity (RAXR) measurements of ion exchange isotherms on a mica basal surface using $\mathrm{Rb}$ as a probe ion. Our predictions of the free energy of exchange (relative to $\mathrm{Cs}$ ) between the solution and the mineral surface are remarkably consistent with the measured values for all ions except $\mathrm{Li}$ (Fig. 7). In the case of $\mathrm{Li}$, our simulations overestimate the relative affinity of Li (vs. Cs) for water vs. the mica-water interface by $20.3 \mathrm{~kJ} \mathrm{~mol}^{-1}$. This discrepancy is close to that by which our simulations overestimate the free energy of hydration of Li relative to Cs $\left(17.8 \mathrm{~kJ} \mathrm{~mol}^{-1}\right)$, suggesting that the Li-water interaction potential parameters used in our simulations may be a significant source of error.

The relatively worse prediction of the solvation and adsorption energetics of Li compared to the other alkali metals is not entirely surprising for two reasons. First, the coordination structure of $\mathrm{Li}^{+}$in water is known to be challenging to reproduce in classical MD simulations. ${ }^{100}$ Second, the Liwater interatomic potential parameters used in the present study were initially developed for use with a polarizable water model. ${ }^{74}$ Nonetheless, the Li potential parameters used here are routinely used in conjunction with the nonpolarizable SPC/E water model and this combination is known to give a reasonable prediction of the four-fold coordination structure of $\mathrm{Li}^{+}$. 101,102

The stronger adsorption of large alkali metals (K, Rb, Cs) relative to smaller metals $(\mathrm{Li}, \mathrm{Na}$ ) was previously interpreted as reflecting the formation of different types of surface complexes (e.g., inner- vs. outer-sphere surface complexes) controlled by the hydration free energy of cations. ${ }^{25}$ The present study, instead, reveals that significant adsorption 
selectivity can result from small differences in the ability of different ions to fit the topographic features of the siloxane surface, associated with adsorption as ISSC1 vs. ISSC2. Our results, as noted above, are broadly consistent with the conceptual view of ion exchange as a partitioning between bulk liquid water and a "sub-aqueous" Stern layer water phase that selectively adsorbs cations of lower hydration energy. ${ }^{90}$ However, the non-monotonic nature of the simulation predictions in Fig. 7 paints a more complex picture in which selectivity is significantly modulated by the ability of surface sites to accommodate the preferred coordination number of each ion.

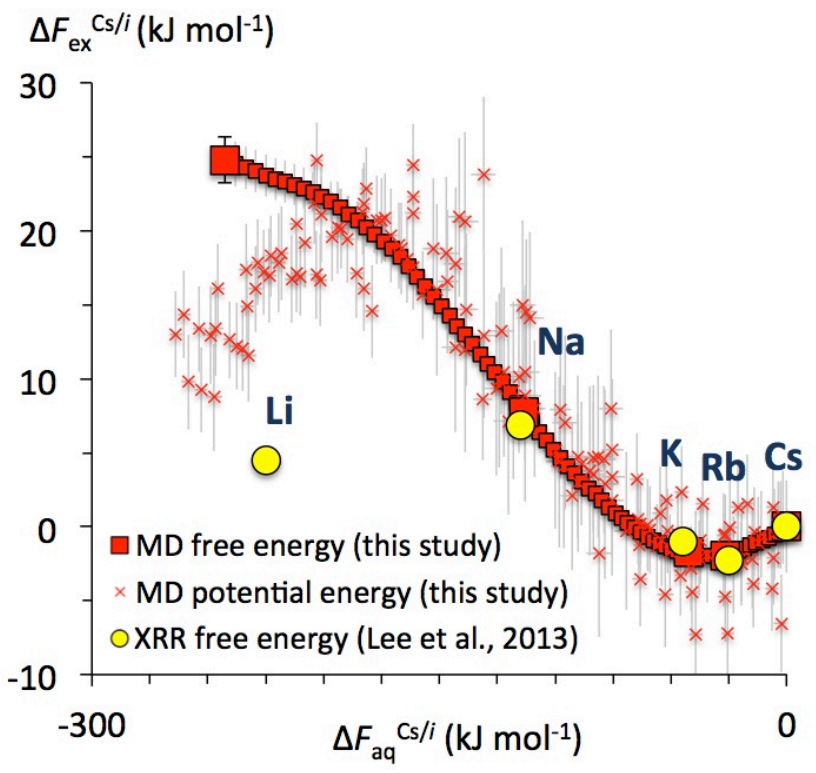

Figure 7. Free energy of cation exchange at the mica-water interface (relative to Cs), plotted as a function of the free energy of hydration (relative to Cs). Yellow circles are experimental Gibbs free energies. ${ }^{25}$ Large red squares are free energies predicted with the thermodynamic integration (TI) technique. Small red squares show intermediate stages of the TI calculation. Red crosses are potential energies at each stage of the TI calculation.

Importance of OSSC on mica. A long-standing question in studies of the EDL on mica is the relative importance of inner-sphere surface complexes vs. longer-ranged adsorption mechanisms (outer-sphere surface complexes, diffuse layer adsorption) in screening the surface charge of mica. As noted in Table SI3, MD simulations with a range of force fields (including those obtained in the present study) predict that alkali metals adsorb predominantly as ISSC. This prediction is consistent with FM-AFM data obtained with Li- and Nabearing mica ${ }^{65}$ and with water vapor adsorption measurements showing that adsorbed ions influence only the first water monolayer. ${ }^{103}$ However, electrokinetic measurements in alkali chloride solutions, when extrapolated to the conditions of our study $(0.1 \mathrm{M})$, yield a zeta potential $\zeta \approx-60 \pm 20$ $\mathrm{mV}$ in the case of Li- and Na-bearing mica and $\zeta \approx 0 \pm 20 \mathrm{mV}$ in the case of $\mathrm{K}$ - and Cs-bearing mica, ${ }^{104}$ indicating a weaker screening of surface charge by the smaller alkali metals. Measurements of the swelling properties of alkali-metalexchanged vermiculite, as well as atomistic-level structures determined by NDIS, suggest that Li has a significant tendency to form OSSC in vermiculite interlayer nanopores, whereas other alkali metals form primarily ISSC. ${ }^{92}$ Surface force apparatus measurements of the normal and shear forces across thin water films between parallel mica surfaces showed a similar behavior between Na- and K-bearing micas $^{105}$ but a very different behavior between Na- and Csbearing mica ${ }^{23,32}$ and between $\mathrm{Li}$ - and Cs-bearing mica, ${ }^{106}$ results interpreted as indicating that $\mathrm{Cs}$ forms primarily ISSC, whereas $\mathrm{Na}, \mathrm{Li}$ and, by extension, $\mathrm{K}$ form primarily OSSC. ${ }^{23,106}$ Finally, RAXR results suggested that Rb adsorbs 85-90\% ICCS from a $3 \mathrm{mM}$ RbCl solution, the rest being adsorbed as OSSC species. ${ }^{46}$ In short, different observations provide sharply differing views of the importance of alkali metal OSSC and diffuse layer species at mica-water interfaces.

In an attempt to shed light onto the disagreements outlined above, we compared the vertical density profile of Rb derived from our MD simulations with that from elementspecific in-situ RAXR data measured in a $3 \mathrm{mM} \mathrm{RbCl}$ solution. ${ }^{46}$ Both results show that $\mathrm{Rb}$ adsorbs dominantly as ISSC, whereas the experimental data also show a minor fraction (10-15\%) of Rb OSSC (Fig. 8a). The RAXR spectra calculated from the MD-derived $\mathrm{Rb}$ profile are compared with the experimental data in Fig. 8b. Overall, there is good agreement between the simulated and measured values. Some differences are observed at several $q$ values, including $q=0.85$ and $1.76 \AA^{-1}$. Variations of the amplitude $\left(A_{\mathrm{R}}\right)$ and phase $\left(\Phi_{\mathrm{R}}\right)$ of the element-specific structure factor of $\mathrm{Rb}^{46,107}$ more clearly show the differences as a function of $q$ (Figs. 8c and d). The calculated $A_{\mathrm{R}}$ values are larger than the measured values at low $q$. This indicates that the calculated Rb coverage is larger than the measured coverage, which can be in part due to the difference in Rb concentration (100 mM vs. 3 $\mathrm{mM})$. From the phase plot, the $\Phi_{\mathrm{R}} / q$ at low $q$ corresponds to the average height of adsorbed $\mathrm{Rb}$ distribution. The calculated $\Phi_{\mathrm{R}}$ values at low $q$ are smaller than the measured values, indicating that the simulation underestimates the fractional coverage of OSSC determined by our previous RAXR measurements. ${ }^{46}$
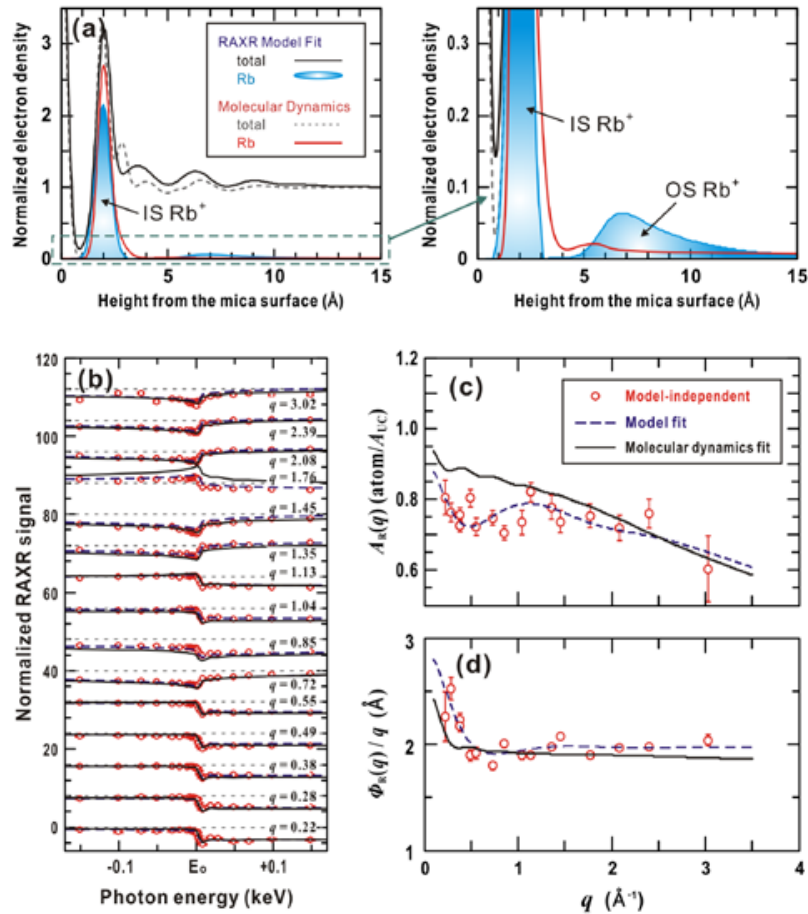
Figure 8. (a) Vertical density profile of Rb counter-ions derived from the conventional model fit of our previously obtained RAXR data ${ }^{46}$ and from MD simulations (this study). The MDderived profile is resolution-broadened and shifted by $\triangle \mathrm{zMD}$ of 0.32(2) $\AA$ from the original profile, as described in the Supporting Information. (b) RAXR data analyses using a conventional model fit $^{46}$ and the $\mathrm{Rb}$ distribution derived from MD simulations. The data are offset vertically (see the dotted lines as the reference) for clarity. Variation of the amplitude, $A_{\mathrm{R}}$, (c) and phase, $\Phi_{\mathrm{R}}$, (d) as a function of $q$ for the element-specific structure factor of Rb adsorbed at the muscovite (001) $-3 \mathrm{mM} \mathrm{RbCl}$ solution interface.

One potential source of this discrepancy is the exact composition of the mica samples used. For example, the mica used by Scales et al. ${ }^{104}$ was reported to have a unit cell formula of $\mathrm{K}_{0.84} \mathrm{Na}_{0.12}\left(\mathrm{Al}_{1.93} \mathrm{Fe}^{\mathrm{II}}{ }_{0.06} \mathrm{Mg}_{0.04}\right)\left(\mathrm{Si}_{3.04} \mathrm{Al}_{0.96}\right) \mathrm{O}_{10}(\mathrm{OH})_{2}$, i.e., $9 \%$ of the structural charge resulted from isomorphic substitutions in the octahedral sheet. Molecular dynamics simulation studies of smectite clay minerals indicate that $\mathrm{Li}$ and $\mathrm{Na}$ form ISSC on tetrahedral charge sites and OSSC on octahedral charge sites, whereas $\mathrm{K}, \mathrm{Rb}$, and Cs form ISSC on all charged surface sites. ${ }^{62,85,108}$ The mica crystals used for both our previous ${ }^{46}$ and current $\mathrm{X}$-ray studies also have a chemical composition that deviates slightly from an ideal mica crystal. ${ }^{39}$ While the good agreement between our simulations and experimental results provides strong evidence that $\mathrm{Rb}$ adsorb predominantly as ISSC, it does not preclude the possibility that a fraction of the other metal ions adsorb as species other than ISSC at natural mica-water interfaces.

Surface complexation modeling. As a final test of the consistency of our XRR and MD simulation results, we developed a surface complexation model of alkali metal adsorption at the mica-water interface based on a simplified version of the three plane model (TPM) formalism. ${ }^{109,110}$ Briefly, we modeled alkali metal surface complexes as forming in three planes at $z=1 \AA$ (plane 0), $2 \AA$ (plane 1), and 4 $\AA$ (plane 2). We assumed that the dielectric constant in the stern layer equals about half of that of bulk liquid water $\left(\varepsilon_{\text {Stern }}=39.2\right){ }^{18,109}$ Based on this assumption, the capacitances of the inter-plane regions were estimated as $C_{p}=$ $\varepsilon_{\text {Stern }} \varepsilon_{0} / \Delta x_{p}$, where $\varepsilon_{0}=8.85419 \times 10^{-12} \mathrm{~F} \mathrm{~m}^{-1}$ is the permittivity of vacuum and $\Delta x_{p}$ is the distance between planes $p$ and $p$ 1 , which yields $C_{1}=3.47 \mathrm{~F} \mathrm{~m}^{-2}$ and $C_{2}=1.74 \mathrm{~F} \mathrm{~m}^{-2}$. The fraction of mica structural charge screened by counter-ion adsorption and co-ion exclusion in the diffuse layer (beyond plane 2) was arbitrarily set to 0.05 . The resulting TPM (described in the Supporting Information) has 15 unknown parameters: the equilibrium constants $K_{\mathrm{M}, p}$ for the adsorption of the five alkali metals $M$ in the three planes $p$. We determined the values of these constants by fitting the model to two datasets: MD simulation prediction of the fraction of alkali metals adsorbed at $z \in[0 \AA ; 1.5 \AA], z \in[1.5 \AA ; 2.5$ $\AA]$, and $z \in[2.5 \AA ; 6 \AA]$ in $0.1 \mathrm{M}$ alkali chloride solutions (Fig. 4); and XRR data on the adsorption of $\mathrm{Rb}$ in $10^{-3} \mathrm{M}$ RbCl-MCl solutions ( $\mathrm{M}=\mathrm{Li}, \mathrm{Na}, \mathrm{K}$, or $\mathrm{Cs}$ ) with a range of Rb:M ratios. ${ }^{25}$ Model predictions show that the TPM formalism is able to describe our XRR data on the cation adsorption selectivity and our MD simulation results on the cation density profiles in a mutually consistent manner (Fig. 9a,c-f). Our surface complexation model predicts that the coexistence of several adsorption planes makes cation exchange on mica non-ideal (Fig. 9b), a finding consistent with the nonideal behavior observed during ion exchange reactions be- tween $\mathrm{Na}, \mathrm{K}$, and $\mathrm{Cs}$ on micaceous minerals (reactions that control the global biogeochemical cycle of potassium and the migration of cesium radioisotopes in the environment). ${ }^{111-113}$
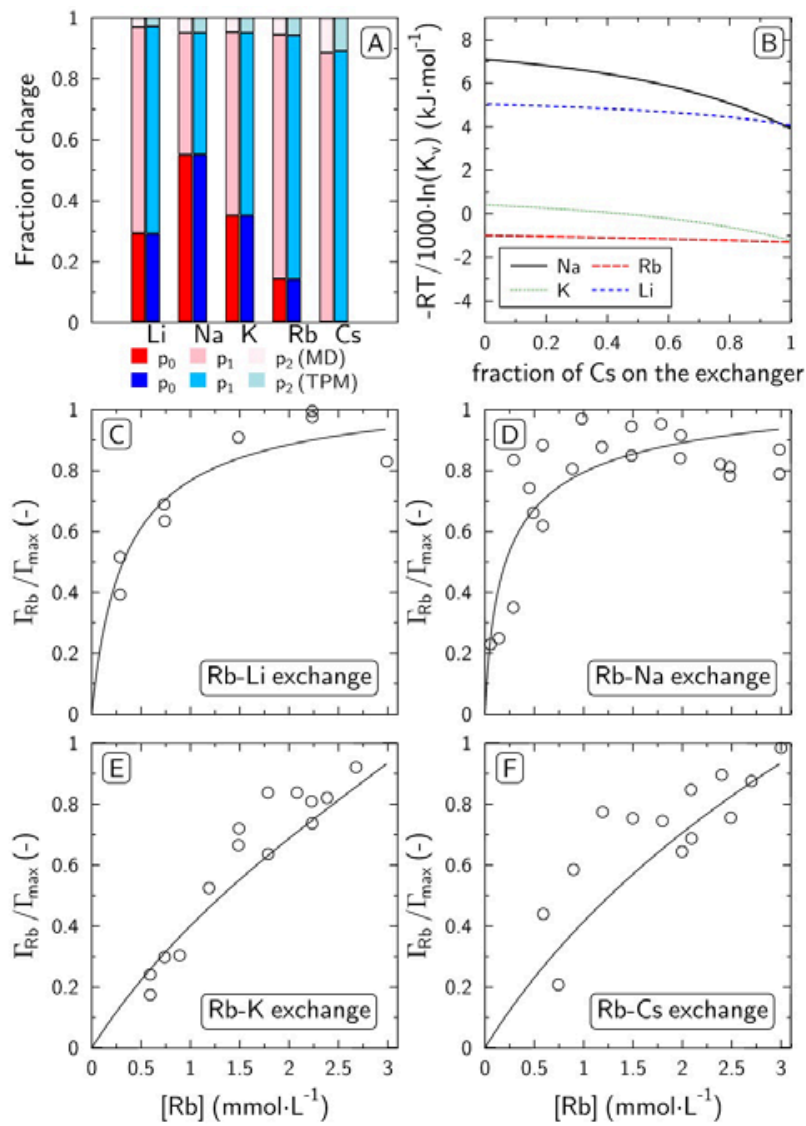

Figure 9. Triple plane model (TPM) calculations compared against XRR and MD simulation results. (a) Fraction of the mica surface charge compensated by counter-ion adsorption in Stern layer planes 0,1 and 2 in $0.1 \mathrm{M} \mathrm{MCl}$ solutions $(\mathrm{M}=\mathrm{Li}$, $\mathrm{Na}, \mathrm{K}, \mathrm{Rb}, \mathrm{Cl}$ ). (b) Free energy of M-Cs exchange (from the TPM prediction of the ion exchange selectivity coefficient, $K_{\mathrm{v}}=$ $a_{\mathrm{M}} \Gamma_{\mathrm{Cs}} / a_{\mathrm{Cs}} \Gamma_{\mathrm{M}}$, where $a_{i}$ is the activity of species $i$ in solution and $\Gamma_{i}$ is the mole fraction of species $i$ on the surface) plotted as a function of $\Gamma$ cs. (c-f) Fraction of the mica surface charge compensated by Stern layer $\mathrm{Rb}$ in $0.003 \mathrm{M} \mathrm{RbCl-MCl}$ aqueous solutions ( $\mathrm{M}=\mathrm{Li}, \mathrm{Na}, \mathrm{K}, \mathrm{Cs})$, plotted as a function Rb concentration in solution [symbols: XRR measurements; ${ }^{25}$ lines: TPM].

As an additional constraint on our surface complexation model, we attempted to fit our MD simulation predictions on the fraction of mica structural charge screened by the diffuse layer in $0.1 \mathrm{M} \mathrm{MCl}$ solutions. This attempt was unsuccessful, because within the framework of the TPM, stronger charge screening in the Stern layer invariably implies stronger adsorption, whereas according to our MD simulations the most weakly adsorbed cations ( $\mathrm{Li}, \mathrm{Na}$ ) have the strongest tendency to screen the mica structural charge within the Stern layer (Fig. SI4). This discrepancy suggests that charge screening at the mica $-0.1 \mathrm{M}$ alkali chloride solution interface may be significantly impacted by specific ion-ion interactions in the EDL (e.g., the formation of adsorbed metal chloride ion pairs), in agreement with the existence of a pronounced chloride density peak at $z \sim 4 \AA$ for all counterions except Li (Fig. SI4). 
Concluding remarks. Our XRR and MD simulation results provide a mutually consistent view of the structure and energetics of the Stern layer at mica-water interfaces that also agrees with high-resolution AFM data. ${ }^{26,35,64,65}$ Overall, our results show that the first water monolayer is primarily structured by its interactions with the surface (it contains three types of water molecules that donate two, one, or zero hydrogen bonds to the mica surface). The second water monolayer is significantly impacted by its interaction with adsorbed ions. Water beyond the first two monolayers exhibits density layering (up to $\sim 10 \AA$ from the surface), but no evidence of sensitivity to short-range interactions with either the surface or adsorbed ions. Alkali metals adsorb primarily as two types of inner-sphere surface complexes, the relative stability of which is determined by the ability of the surface to satisfy the preferred coordination number of each metal.

\section{ASSOCIATED CONTENT}

\section{Supporting Information}

Additional detail on the XRR, MD, TI, and surface complexation modeling methodologies and on the comparison with previous MD simulation results, are provided in the Supporting Information (PDF).

\section{AUTHOR INFORMATION}

\section{Corresponding Author}

*bourg@princeton.edu

\section{Author Contributions}

The manuscript was written through contributions of all authors. IB carried out the MD simulations; SSL and PF carried out the XRR experiments; CT carried out the surface complexation modeling.

\section{ACKNOWLEDGMENT}

This work was supported by U.S. Department of Energy, Office of Science, Office of Basic Energy Sciences, Chemical Sciences, Geosciences, and Biosciences Division under Contracts DEAC02-05CH11231 to the University of California as operator of the Lawrence Berkeley National Laboratory and DE-AC0206CH11357 to UChicago Argonne, LLC as operator of Argonne National Laboratory. The manuscript was created at Princeton University and UChicago Argonne, LLC, Operator of Argonne National Laboratory (“Argonne”). Argonne, a US Department of Energy Office of Science laboratory, is operated under Contract DE-AC02-06CH11357. The US Government retains for itself, and others acting on its behalf, a paid-up nonexclusive, irrevocable worldwide license in said article to reproduce, prepare derivative works, distribute copies to the public, and perform publicly and display publicly, by or on behalf of the Government. The X-ray data were collected at beamline 6-ID-B, Advanced Photon Source. Use of the Advanced Photon Source was supported by the U.S. Department of Energy, Office of Science, Office of Basic Energy Sciences, under Contract DEAC02-06CH11357 to UChicago Argonne, LLC as operator of Argonne National Laboratory. The MD simulations reported in this manuscript were carried out using resources of the National Energy Research Scientific Computing Center (NERSC), which is supported by the U.S. Department of Energy, Office of Science, Office of Basic Energy Sciences, under Contract DEAC02-05CH11231 to the University of California. CT acknowledges funding from the CNRS-NEEDS project TRANSREAC.

\section{REFERENCES}

(1) Schoch, R. B.; Han, J.; Renaud, P. Transport Phenomena in Nanofluidics. Rev. Mod. Phys. 2008, 80, 839-883.

(2) Yusko, E. C.; An, R.; Mayer, M. Electroosmotic Flow Can Generate Ion Current Rectification in Nano- and Micropores. ACS Nano 2010, 4, 477-487.

(3) Mattia, D.; Leese, H.; Calabrò, F. Electro-Osmotic Flow Enhancement in Carbon Nanotube Membranes. Philos. Trans. R. Soc. A 2016, 374, 20150268.

(4) Honig, B.; Nicholls, A. Classical Electrostatics in Biology and Chemistry. Science 1995, 268, 1144-1149.

(5) Boda, D.; Valiskó, M.; Henderson, D.; Gillespie, D.; Eisenberg, B.; Gilson, M. K. Ions and Inhibitors in the Binding Site of HIV Protease: Comparison of Monte Carlo Simulations and the Linearized Poisson-Boltzmann Theory. Biophys. J. 2009, 96, 1293-1306.

(6) Israelachvili, J.; Wennerström, H. Role of Hydration and Water Structure in Biological and Colloidal Interactions. Nature 1996, 379, 219-225.

(7) Shin, S.; Um, E.; Sabass, B.; Ault, J. T.; Rahimi, M.; Warren, P. B.; Stone, H. A. Size-Dependent Control of Colloid Transport via Solute Gradients in Dead-End Channels. Proc. Natl. Acad. Sci. U. S. A. 2015, 113, 257-261.

Ding, Z.; Kloprogge, J. T.; Frost, R. L. Porous Clays and Pillared Clays-Based Catalysts. Part 2: A Review of the Catalytic and Molecular Sieve Applications. J. Porous Mater. 2002, 8, 273-293.

(9) Arnold, J.; Kosson, D. S. S.; Garrabrants, A.; Meeussen, J. C. L. C. L.; van der Sloot, H. A. A. Solution of the Nonlinear Poisson-Boltzmann Equation: Application to Ionic Diffusion in Cementitious Materials. Cem. Concr. Res. 2013, 44, 8-17. Brown, Jr., G. E. How Minerals React with Water. Science 2001, 294, 67-70.

Zachara, J.; Brantley, S.; Chorover, J.; Ewing, R.; Kerisit, S.; Liu, C.; Perfect, E.; Rother, G.; Stack, A. G. Internal Domains of Natural Porous Media Revealed: Critical Locations for Transport, Storage, and Chemical Reaction. Environ. Sci. Technol. 2016, 50, 2811-2829.

(12) Dash, J. G.; Rempel, A. W.; Wettlaufer, J. S. The Physics of Premelted Ice and Its Geophysical Consequences. Rev. Mod. Phys. 2006, 78, 695-741.

(13) Liu, L. Prediction of Swelling Pressures of Different Types of Bentonite in Dilute Solutions. Colloids Surfaces A 2013, 434, 303-318.

(14) Tinnacher, R. M.; Holmboe, M.; Tournassat, C.; Bourg, I. C.; Davis, J. A. Ion Adsorption and Diffusion in Smectite: Molecular, Pore, and Continuum Scale Views. Geochim. Cosmochim. Acta 2016, 177, 130-149.

(15) Sposito, G. The Surface Chemistry of Natural Particles; Oxford University Press, 2004.

(16) Henderson, D.; Boda, D. Insights from Theory and Simulation on the Electrical Double Layer. Phys. Chem. Chem. Phys. 2009, 11, 3822-3830.

(17) Lee, S. H.; Rossky, P. J. A Comparison of the Structure and Dynamics of Liquid Water at Hydrophobic and Hydrophilic Surfaces—a Molecular Dynamics Simulation Study. J. Chem. Phys. 1994, 100, 3334-3345.

(18) Wander, M. C. F.; Clark, A. E. Structural and Dielectric Properties of Quartz-Water Interfaces. J. Phys. Chem. C 2008, 112, 19986-19994.

(19) Bourg, I. C.; Sposito, G. Molecular Dynamics Simulations of the Electrical Double Layer on Smectite Surfaces Contacting Concentrated Mixed Electrolyte $\left(\mathrm{NaCl}-\mathrm{CaCl}_{2}\right)$ Solutions. J. Colloid Interface Sci. 2011, 360, 701-715.

(20) Botan, A.; Marry, V.; Rotenberg, B.; Turq, P.; Noetinger, B. How Electrostatics Influences Hydrodynamic Boundary Conditions: Poiseuille and Electro-Osmotic Flows in Clay Nanopores. J. Phys. Chem. C 2013, 117, 978-985.

(21) Bedzyk, M. J.; Bommarito, G. M.; Caffrey, M.; Penner, T. L. Diffuse-Double Layer at a Membrane-Aqueous Interface Measured with X-Ray Standing Waves. Science 1990, 248, $52-56$.

(22) Tournassat, C.; Chapron, Y.; Leroy, P.; Bizi, M.; Boulahya, F. Comparison of Molecular Dynamics Simulations with Triple Layer and Modified Gouy-Chapman Models in a $0.1 \mathrm{M}$ NaCl-montmorillonite System. J. Colloid Interface Sci. 2009, 
Perkin, S.; Goldberg, R.; Chai, L.; Kampf, N.; Klein, J. Dynamics Properties of Confined Hydration Layers. Faraday Discuss. 2009, 141, 399-413.

(24) Watkins, M.; Berkowitz, M. L.; Shluger, A. L. Role of Water in Atomic Resolution AFM in Solutions. Phys. Chem. Chem. Phys. 2011, 13, 12584-12594.

(25) Lee, S. S.; Fenter, P.; Nagy, K. L.; Sturchio, N. C. Changes in Adsorption Free Energy and Speciation during Competitive Adsorption between Monovalent Cations at the Muscovite (001)-Water Interface. Geochim. Cosmochim. Acta 2013, 123, 416-426.

(26) Ricci, M.; Spijker, P.; Voïtchovsky, K. Water-Induced Correlation between Single Ions Imaged at the Solid-liquid Interface. Nat. Commun. 2014, 5, 4400.

(27) Torrie, G. M.; Patey, G. N. Molecular Solvent Model for an Electrical Double Layer: Asymmetric Solvent Effects. J. Phys. Chem. 1993, 97, 12909-12918.

(28) Merlet, C.; Limmer, D. T.; Salanne, M.; van Roij, R.; Madden, P. A.; Chandler, D.; Rotenberg, B. The Electric Double Layer Has a Life of Its Own. J. Phys. Chem. C 2014, 118, 18291-18298.

(29) Siretanu, I.; Ebeling, D.; Andersson, M. P.; Stipp, S. L. S.; Philipse, A.; Stuart, M. C.; van den Ende, D.; Mugele, F. Direct Observation of Ionic Structure at Solid-Liquid Interfaces: A Deep Look into the Stern Layer. Sci. Rep. 2014, 4, 4956.

(30) Leroy, P.; Tournassat, C.; Bizi, M. Influence of Surface Conductivity on the Apparent Zeta Potential of $\mathrm{TiO}_{2}$ Nanoparticles. J. Colloid Interface Sci. 2011, 356, 442-453.

(31) Gonella, G.; Lütgebaucks, C.; de Beer, A. G. F.; Roke, S. Second Harmonic and Sum-Frequency Generation from Aqueous Interfaces Is Modulated by Interference. J. Phys. Chem. C 2016, 120, 9165-9173.

(32) Goldberg, R.; Chai, L.; Perkin, S.; Kampf, N.; Klein, J. Breakdown of Hydration Repulsion between Charged Surfaces in Aqueous $\mathrm{Cs}^{+}$Solutions. Phys. Chem. Chem. Phys. 2008, 10, 4939-4945.

(33) Fukuma, T.; Ueda, Y.; Yoshioka, S.; Asakawa, H. AtomicScale Distribution of Water Molecules at the Mica-Water Interface Visualized by Three-Dimensional Scanning Force Microscopy. Phys. Rev. Lett. 2010, 104, 16101.

(34) Kilpatrick, J. I.; Loh, S. H.; Jarvis, S. P. Directly Probing the Effects of Ions on Hydration Forces at Interfaces. $\mathrm{J}$. Am. Chem. Soc. 2013, 135, 2628-2634.

(35) Kobayashi, K.; Oyabu, N.; Kimura, K.; Ido, S.; Suzuki, K.; Imai, T.; Tagami, K.; Tsukada, M.; Yamada, H. Visualization of Hydration Layers on Muscovite Mica in Aqueous Solution by Frequency-Modulation Atomic Force Microscopy. $J$. Chem. Phys. 2013, 138, 184704.

(36) Kumar, N.; Zhao, C.; Klaassen, A.; van den Ende, D.; Mugele, F.; Siretanu, I. Characterization of the Surface Charge Distribution on Kaolinite Particles Using High Resolution Atomic Force Microscopy. Geochim. Cosmochim. Acta 2016, $175,100-112$

(37) Kobayashi, K.; Liang, Y.; Amano, K.-I.; Murata, S.; Matsuoka, T.; Takahashi, S.; Nishi, N.; Sakka, T. Molecular Dynamics Simulation of Atomic Force Microscopy at the Water-Muscovite Interface: Hydration Layer Structure and Force Analysis. Langmuir 2016, 32, 3608-3616.

(38) Park, C.; Fenter, P. A.; Nagy, K. L.; Sturchio, N. C. Hydration and Distribution of Ions at the Mica-Water Interface. Phys. Rev. Lett. 2006, 97, 16101.

(39) Schlegel, M. L.; Nagy, K. L.; Fenter, P.; Cheng, L.; Sturchio, N. C.; Jacobsen, S. D. Cation Sorption on the Muscovite (001) Surface in Chloride Solutions Using High-Resolution X-Ray Reflectivity. Geochim. Cosmochim. Acta 2006, 70, 35493565.

(40) Zhang, Z.; Fenter, P.; Sturchio, N. C.; Bedzyk, M. J.; Machesky, M. L.; Wesolowski, D. J. Structure of Rutile $\mathrm{TiO}_{2}$

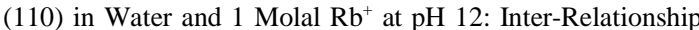
among Surface Charge, Interfacial Hydration Structure, and Substrate Structural Displacements. Surf. Sci. 2007, 601, 1129-1143.

(41) Luo, G.; Malkova, S.; Yoon, J.; Schultz, D. G.; Lin, B.;
Meron, M.; Benjamin, I.; Vanysek, P.; Schlossman, M. L. Ion Distributions near a Liquid-Liquid Interface. Science 2006, 311, 216-218.

Fenter, P.; Cheng, L.; Rihs, S.; Machesky, M.; Bedzyk, M. J.; Sturchio, N. C. Electrical Double-Layer Structure at the Rutile-Water Interface as Observed in Situ with Small-Period X-Ray Standing Waves. J. Colloid Interface Sci. 2000, 225, 154-165.

(43) Zhang, Z.; Fenter, P.; Cheng, L.; Sturchio, N. C.; Bedzyk, M. J.; Predota, M.; Bandura, A.; Kubicki, J. D.; Lvov, S. N.; Cummings, P. T., et al. Ion Adsorption at the Rutile-Water Interface: Linking Molecular and Macroscopic Properties. Langmuir 2004, 20, 4954-4969.

(44) Nemšák, S.; Shavorskiy, A.; Karslioglu, O.; Zegkinoglou, I.; Rattanachata, A.; Conlon, C. S.; Keqi, A.; Greene, P. K.; Burks, E. C.; Salmassi, F., et al. Concentration and ChemicalState Profiles at Heterogeneous Interfaces with Sub-Nm Accuracy from Standing-Wave Ambient-Pressure Photoemission. Nat. Commun. 2014, 5, 5441.

(45) Lee, S. S.; Fenter, P.; Park, C.; Sturchio, N. C.; Nagy, K. L. Hydrated Cation Speciation at the Muscovite (001)-Water Interface. Langmuir 2010, 26, 16647-16651.

(46) Lee, S. S.; Fenter, P.; Nagy, K. L.; Sturchio, N. C. Monovalent Ion Adsorption at the Muscovite (001)-Solution Interface: Relationships among Ion Coverage and Speciation, Interfacial Water Structure, and Substrate Relaxation. Langmuir 2012, 28, 8637-8650.

(47) Bellucci, F.; Lee, S. S.; Kubicki, J. D.; Bandura, A.; Zhang, Z.; Wesolowski, D. J.; Fenter, P. Rb ${ }^{+}$Adsorption at the quartz(101)-Aqueous Interface: Comparison of Resonant Anomalous X-Ray Reflectivity with Ab Initio Calculations. $J$. Phys. Chem. C 2015, 119, 4778-4788.

(48) Kohli, V.; Zhang, Z.; Park, C.; Fenter, P. Rb and Sr Adsorption at the $\mathrm{TiO}_{2}$ (110)-Electrolyte Interface Observed with Resonant Anomalous X-Ray Reflectivity. Langmuir 2010, 26, 950-958.

(49) Predota, M.; Zhang, Z.; Fenter, P.; Wesolowski, D. J.; Cummings, P. T. Electric Double Layer at the Rutile (110) Surface. 2. Adsorption of Ions from Molecular Dynamics and X-Ray Experiments. J. Phys. Chem. B 2004, 108, 1206112072.

(50) Wang, J.; Kalinichev, A. G.; Kirkpatrick, R. J.; Cygan, R. T. Structure, Energetics, and Dynamics of Water Adsorbed on the Muscovite (001) Surface: A Molecular Dynamics Simulation. J. Phys. Chem. B 2005, 109, 15893-15905.

(51) Sakuma, H.; Kawamura, K. Structure and Dynamics of Water on $\mathrm{Li}^{+}-, \mathrm{Na}^{+}-, \mathrm{K}^{+}$-, $\mathrm{Cs}^{+}-, \mathrm{H}_{3} \mathrm{O}^{+}$-Exchanged Muscovite Surfaces: A Molecular Dynamics Study. Geochim. Cosmochim. Acta 2011, 75, 63-81.

(52) Bonthuis, D. J.; Netz, R. R. Beyond the Continuum: How Molecular Solvent Structure Affects Electrostatics and Hydrodynamics at Solid-Electrolyte Interfaces. J. Phys. Chem. B 2013, 117, 11397-11413.

(53) Ohtaki, H.; Radnai, T. Structure and Dynamics of Hydrated Ions. Chem. Rev. 1993, 93, 1157-1204.

(54) Peña, J.; Kwon, K. D.; Refson, K.; Bargar, J. R.; Sposito, G. Mechanisms of Nickel Sorption by a Bacteriogenic Birnessite. Geochim. Cosmochim. Acta 2010, 74, 3076-3089.

(55) Marry, V.; Dubois, E.; Malikova, N.; Durand-Vidal, S.; Longeville, S.; Breu, J. Water Dynamics in Hectorite Clays: Influence of Temperature Studied by Coupling Neutron Spin Echo and Molecular Dynamics. Environ. Sci. Technol. 2011, 45, 2850-2855.

(56) Skelton, A. A.; Fenter, P.; Kubicki, J. D.; Wesolowski, D. J.; Cummings, P. T. Simulations of the Quartz (1011)/Water Interface: A Comparison of Classical Force Fields, Ab Initio Molecular Dynamics, and X-Ray Reflectivity Experiments. J. Phys. Chem. C 2011, 115, 2076-2088.

(57) Fenter, P.; Lee, S. S. Hydration Layer Structure at Solid/water Interfaces. MRS Bull. 2014, 39, 1056-1061.

(58) Park, S.-H.; Sposito, G. Structure of Water Adsorbed on a Mica Surface. Phys. Rev. Lett. 2002, 89, 85501.

(59) Sakuma, H.; Kawamura, K. Structure and Dynamics of Water on Muscovite Mica Surfaces. Geochim. Cosmochim. Acta 2009, 73, 4100-4110. 
(60) Sakuma, H.; Kondo, T.; Nakao, H.; Shiraki, K.; Kawamura, K. Structure of Hydrated Sodium Ions and Water Molecules Adsorbed on the Mica/Water Interface. J. Phys. Chem. C 2011, 115, 15959-15964.

(61) Fenter, P.; Kerisit, S.; Raiteri, P.; Gale, J. D. Is the Calcite Water Interface Understood? Direct Comparisons of Molecular Dynamics Simulations with Specular X-ray Reflectivity Data. J. Phys. Chem. C 2013, 117, 5028-5042.

(62) Sposito, G.; Skipper, N. T.; Sutton, R.; Park, S.-H.; Soper, A. K.; Greathouse, J. A. Surface Geochemistry of the Clay Minerals. Proc. Natl. Acad. Sci. U. S. A. 1999, 96, 3358-3364.

(63) Israelachvili, J. N.; Pashley, R. M. Molecular Layering of Water at Surfaces and Origin of Repulsive Hydration Forces. Nature 1983, 306, 249-250.

(64) Hu, J.; Xiao, X.-D.; Ogletree, D. F.; Salmeron, M. Imaging the Condensation and Evaporation of Molecularly Thin Films of Water with Nanometer Resolution. Science 1995, 268, 267269.

(65) Loh, S.-H.; Jarvis, S. P. Visualization of Ion Distribution at the Mica-Electrolyte Interface. Langmuir 2010, 26, 91769178.

(66) Bourg, I. C.; Sposito, G. Connecting the Molecular Scale to the Continuum Scale for Diffusion Processes in Smectite-Rich Porous Media. Environ. Sci. Technol. 2010, 44, 2085-2091.

(67) Ferrage, E.; Sakharov, B. A.; Michot, L. J.; Delville, A.; Bauer, A.; Lanson, B.; Grangeon, S.; Frapper, G.; JiménezRuiz, M.; Cuello, G. J. Hydration Properties and Interlayer Organization of Water and Ions in Synthetic Na-Smectite with Tetrahedral Layer Charge. Part 2. Toward a Precise Coupling between Molecular Simulations and Diffraction Data. J. Phys. Chem. C 2011, 115, 1867-1881.

(68) Bourg, I. C.; Steefel, C. I. Molecular Dynamics Simulations of Water Structure and Diffusion in Silica Nanopores. J. Phys. Chem. C 2012, 116, 11556-11564.

(69) Holmboe, M.; Bourg, I. C. Molecular Dynamics Simulations of Water and Sodium Diffusion in Smectite Interlayer Nanopores as a Function of Pore Size and Temperature. $J$. Phys. Chem. C 2014, 118, 1001-1013.

(70) Plimpton, S. Fast Parallel Algorithms for Short-Range Molecular Dynamics. J. Comput. Phys. 1995, 117, 1-19.

(71) Catti, M.; Ferraris, G.; Hull, S.; Pavese, A. Powder Neutron Diffraction Study of 2M1 Muscovite at Room Pressure and at 2 GPa. Eur. J. Mineral. 1994, 6, 171-178.

(72) Berendsen, H. J. C.; Grigera, J. R.; Straatsma, T. P. The Missing Term in Effective Pair Potentials. J. Phys. Chem. 1987, 91, 6269-6271.

(73) Cygan, R. T.; Liang, J.-J.; Kalinichev, A. G. Molecular Models of Hydroxide, Oxyhydroxide, and Clay Phases and the Development of a General Force Field. J. Phys. Chem. B 2004, 108, 1255-1266.

(74) Dang, L. X. Development of Nonadditive Intermolecular Potentials Using Molecular Dynamics: Solvation of $\mathrm{Li}^{+}$and $\mathrm{F}^{-}$ Ions in Polarizable Water. J. Chem. Phys. 1992, 96, 69706977.

(75) Dang, L. X. Mechanism and Thermodynamics of Ion Selectivity in Aqueous Solutions of 18-Crown-6 Ether: A Molecular Dynamics Study. J. Am. Chem. Soc. 1995, 117, 6954-6960.

(76) Frenkel, D.; Smit, B. Understanding Molecular Simulation; Academic Press, 2002.

(77) Rotenberg, B.; Morel, J.-P.; Marry, V.; Turq, P.; MorelDesrosiers, N. On the Driving Force of Cation Exchange in Clays: Insights from Combined Microcalorimetry Experiments and Molecular Simulation. Geochim. Cosmochim. Acta 2009, 73, 4034-4044.

(78) Marcus, Y. Thermodynamics of Solvation of Ions. Part 5. Gibbs Free Energy of Hydration at 298.15 K. J. Chem. Soc., Faraday Trans. 1991, 87, 2995-2999.

(79) Fenter, P.; Catalano, J. G.; Park, C.; Zhang, Z. On the Use of CCD Area Detectors for High-Resolution Specular X-Ray Reflectivity. J. Synchrotron Radiat. 2006, 13, 293-303.

(80) Wilson, J.; Cuadros, J.; Cressey, G. An in-Situ Time-Resolved XRD-PSD Investigation into Na-Montmorillonite Interlayer and Particle Rearrangement during Dehydration. Clays Clay Miner. 2004, 52, 180-191.
(81) Holmboe, M.; Wold, S.; Jonsson, M. Porosity Investigation of Compacted Bentonite Using XRD Profile Modeling. $J$. Contam. Hydrol. 2012, 128, 19-32.

(82) Cheng, L.; Fenter, P.; Nagy, K. L.; Schlegel, M. L.; Sturchio, N. C. Molecular-Scale Density Oscillations in Water Adjacent to a Mica Surface. Phys. Rev. Lett. 2001, 87, 156103.

(83) Toney, M. F.; Howard, J. N.; Richer, J.; Borges, G. L.; Gordon, J. G.; Melroy, O. R.; Wiesler, D. G.; Yee, D.; Sorensen, L. B. Distribution of Water Molecules at $\mathrm{Ag}(111) /$ electrolyte Interface as Studied with Surface X-Ray Scattering. Surf. Sci. 1995, 335, 326-332.

(84) Fenter, P.; Lee, S. S.; Skelton, A. A.; Cummings, P. T. Direct and Quantitative Comparison of Pixelated Density Profiles with High-Resolution X-Ray Reflectivity Data. J. Synchrotron Radiat. 2011, 18, 257-265.

(85) Bourg, I. C.; Sposito, G. Ion Exchange Phenomena. In Handbook of Soil Science; Huang, P. M., Li, Y., Sumner, M. E., Eds.; 2011.

(86) Varma, S.; Rempe, S. B. Coordination Numbers of Alkali Metal Ions in Aqueous Solutions. Biophys. Chem. 2006, 124 192-199.

(87) Antognozzi, M.; Humphris, A. D. L.; Miles, M. J. Observation of Molecular Layering in a Confined Water Film and Study of the Layers Viscoelastic Properties. Appl. Phys. Lett. 2001, 78 (3), 300-302.

(88) Omta, A. W.; Kropman, M. F.; Woutersen, S.; Bakker, H. J. Negligible Effect of Ions on the Hydrogen-Bond Structure in Liquid Water. Science 2003, 301, 347-349.

(89) Laird, D. A.; Shang, C. Relationship between Cation Exchange Selectivity and Crystalline Swelling in Expanding 2:1 Phyllosilicates. Clays Clay Miner. 1997, 45, 681-689.

(90) Teppen, B. J.; Miller, D. M. Hydration Energy Determines Isovalent Cation Exchange Selectivity by Clay Minerals. Soil Sci. Soc. Am. J. 2006, 70, 31-40.

(91) Leng, Y.; Cummings, P. T. Hydration Structure of Water Confined between Mica Surfaces. J. Chem. Phys. 2006, 124, 74711.

(92) Skipper, N. T.; Smalley, M. V.; Williams, G. D.; Soper, A. K.; Thompson, C. H. Direct Measurement of the Electric DoubleLayer Structure in Hydrated Lithium Vermiculite Clays by Neutron Diffraction. J. Phys. Chem. 1995, 99, 14201-14204.

(93) Rotenberg, B.; Patel, A. J.; Chandler, D. Molecular Explanation for Why Talc Surfaces Can Be Both Hydrophilic and Hydrophobic. J. Am. Chem. Soc. 2011, 133, 2052120527.

(94) Teich-McGoldrick, S. L.; Greathouse, J. A.; Cygan, R. T. Molecular Dynamics Simulations of Uranyl Adsorption and Structure on the Basal Surface of Muscovite. Mol. Simul. 2014, 40, 610-617.

(95) Dequidt, A.; Devémy, J.; Malfreyt, P. Confined KCl Solution between Two Mica Surfaces: Equilibrium and Frictional Properties. J. Phys. Chem. C 2015, 119, 22080-22085.

(96) Kerisit, S.; Okumura, M.; Rosso, K. M.; Machida, M. Molecular Simulation of Cesium Adsorption at the Basal Surface of Phyllosilicate Minerals. Clays Clay Miner. 2016, 64, 389-400.

(97) Meleshyn, A. Aqueous Solution Structure at the Cleaved Mica Surface: Influence of $\mathrm{K}^{+}, \mathrm{H}_{3} \mathrm{O}^{+}$, and $\mathrm{Cs}^{+}$Adsorption. J. Phys. Chem. C 2008, 112, 20018-20026.

(98) Meleshyn, A. Potential of Mean Force for $\mathrm{K}^{+}$in Thin Water Films on Cleaved Mica. Langmuir 2010, 26, 13081-13085.

(99) Leng, Y. Hydration Force between Mica Surfaces in Aqueous KCl Electrolyte Solution. Langmuir 2012, 28, 5339-5349.

(100) Rempe, S. B.; Pratt, L. R.; Hummer, G.; Kress, J. D.; Martin, R. L.; Redondo, A. The Hydration Number of $\mathrm{Li}^{+}$in Liquid Water. J. Am. Chem. Soc. 2000, 122, 966-967.

(101) Koneshan, S.; Rasaiah, J. C.; Lynden-Bell, R. M.; Lee, S. H. Solvent Structure, Dynamics, and Ion Mobility in Aqueous Solutions at $25^{\circ} \mathrm{C}$. J. Phys. Chem. B 1998, 102, 4193-4204.

(102) Møller, K. B.; Rey, R.; Masia, M.; Hynes, J. T. On the Coupling Between Molecular Diffusion and Solvation Shell Exchange. J. Chem. Phys. 2005, 122, 114508.

(103) Balmer, T. E.; Christenson, H. K.; Spencer, N. D.; Heuberger, M. The Effect of Surface Ions on Water Adsorption to Mica. Langmuir 2008, 24, 1566-1569. 
(104) Scales, P. J.; Grieser, F.; Healy, T. W. Electrokinetics of the Muscovite Mica-Aqueous Solution Interface. Langmuir 1990, 6, 582-589.

(105) Raviv, U.; Klein, J. Fluidity of Bound Hydration Layers. Science 2002, 297, 1540-1543.

(106) Baimpos, T.; Shrestha, B. R.; Raman, S.; Valtiner, M. Effect of Interfacial Ion Structuring on Range and Magnitude of Electric Double Layer, Hydration, and Adhesive Interactions between Mica Surfaces in $0.05-3 \mathrm{M} \mathrm{Li}^{+}$and $\mathrm{Cs}^{+}$Electrolyte Solutions. Langmuir 2014, 30, 4322-4332.

(107) Park, C.; Fenter, P. A.; Sturchio, N. C.; Nagy, K. L Thermodynamics, Interfacial Structure, and $\mathrm{pH}$ Hysteresis of $\mathrm{Rb}^{+}$and $\mathrm{Sr}^{2+}$ Adsorption at the Muscovite (001)-Solution Interface. Langmuir 2008, 24, 13993-14004.

(108) Chang, F.-R. C.; Skipper, N. T.; Sposito, G. Computer Simulation of Interlayer Molecular Structure in Sodium Montmorillonite Hydrates. Langmuir 1995, 11, 2734-2741.

(109) Hiemstra, T.; Van Riemsdijk, W. H. On the Relationship between Charge Distribution, Surface Hydration, and the Structure of the Interface of Metal Hydroxides. J. Colloid
Interface Sci. 2006, 301, 1-18.

(110) Goldberg, S.; Criscenti, L. J.; Turner, D. R.; Davis, J. A.; Cantrell, K. J. Adsorption-Desorption Processes in Subsurface Reactive Transport Modeling. Vadose Zone J. 2007, 6, 407435.

(111) Poinssot, C.; Baeyens, B.; Bradbury, M. H. Experimental and Modelling Studies of Caesium Sorption on Illite. Geochim. Cosmochim. Acta 1999, 63, 3217-3227.

(112) Tournassat, C.; Gailhanou, H.; Crouzet, C.; Braibant, G.; Gautier, A.; Lassin, A.; Blanc, P.; Gaucher, E. C. Two Cation Exchange Models for Direct and Inverse Modelling of Solution Major Cation Composition in Equilibrium with Illite Surfaces. Geochim. Cosmochim. Acta 2007, 71, 1098-1114.

(113) Lammers, L. N.; Bourg, I. C.; Okumura, M.; Kolluri, K.; Sposito, G. Molecular Dynamics Simulations of Cesium Adsorption on Illite Nanoparticles. J. Colloid Interface Sci. 2017, 490, 608-620. 


\section{TOC Graphic}
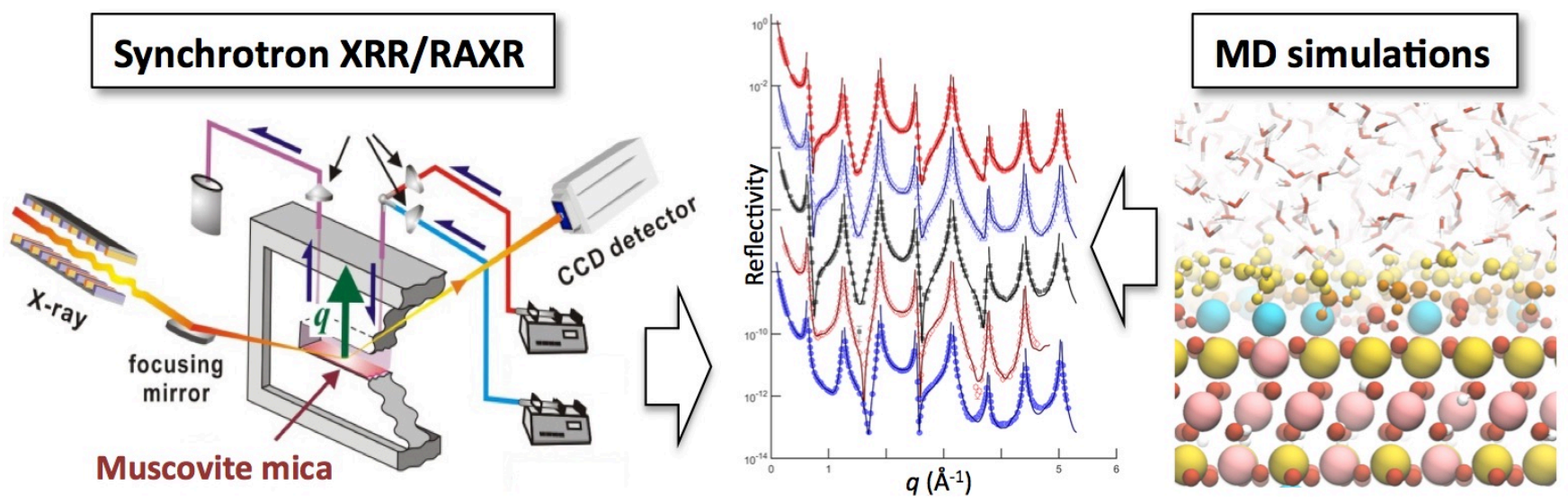